\title{
Left ventricular function in persistent pulmonary hypertension of the newborn Computer analysis of the echocardiogram
}

\author{
MARTIN G ST JOHN SUTTON, RICHARD A MEYER \\ From the Division of Pediatric Cardiology, Children's Hospital Medical Center, Cincinnati, Ohio; and the Division \\ of Cardiology, University of Pennsylvania, Pennsylvania, USA
}

SUMMARY Regional and global left ventricular function was assessed in 23 neonates with persistent pulmonary hypertension using computer assisted analysis of their left ventricular echocardiograms and compared with that in $\mathbf{5 0}$ healthy neonates. End diastolic left ventricular dimension was normal and end systolic dimension increased while percentage left ventricular shortening and peak velocity of circumferential fibre shortening decreased indicating impaired systolic performance. The peak rate of increase in left ventricular diameter in early diastole was significantly decreased and the durations of the rapid filling and isovolumic relaxation periods were prolonged suggesting resistance to left ventricular filling due to changes in diastolic myocardial properties. This abnormal left ventricular cavity function may have been due to a combination of increased diastolic wall thickness, reduced percentage systolic wall thickening, increased relative wall thickness, and pronounced reduction in peak rates of systolic wall thickening and diastolic wall thinning

Seven neonates with persistent pulmonary hypertension died, and of the three examined at necropsy all had left ventricular hypertrophy and two extensive subendocardial haemorrhage and infarction affecting the right and left ventricular papillary muscles. Thus left ventricular dysfunction appears to be a common feature in neonates with this disorder and may be readily detected using computer analysis of left ventricular echocardiograms. Unfortunately, no single echo measurement was useful prognostically. Left ventricular dysfunction in persistent pulmonary hypertension probably results from a combination of hypoxaemia, acidaemia, and pulmonary hypertension, and although it may contribute to the high mortality in this syndrome, a correlation between the severity of left ventricular dysfunction and clinical outcome could not be shown.

Persistent pulmonary hypertension of the newborn, or persistent fetal circulation, describes a syndrome occurring in normal birthweight neonates with normal cardiac anatomy in whom the pulmonary vascular resistance fails to fall in the immediate neonatal period. ${ }^{1-4}$ This results in reduced pulmonary blood flow, persistent pulmonary hypertension, tachypnoea, acidaemia, and cyanosis due to right to left shunting via the ductus arteriosus and the foramen ovale. ${ }^{4-6}$ In most infants with this disorder no definitive pre-

Presented in part at the annual scientific sessions of the American College of Cardiology.

Work supported by the American Heart Association, Southwest Ohio Chapter, and NIH grant RRO7.

Accepted for publication 29 June 1983 cipitating or causative factor is apparent. ${ }^{4-6}$

The presence of left ventricular dysfunction has recently been recognised and may possibly contribute to the unacceptably high mortality rate.$^{6-8}$ The purpose of this study was to assess the frequency and severity of left ventricular dysfunction in persistent pulmonary hypertension and to determine whether or not its presence affected prognosis or contributed to mortality. To achieve these aims we used computer assisted analysis of the left ventricular echocardiograms, a technique that has been used to evaluate both diastolic and systolic global and regional function in children and adults. ${ }^{9-12}$ Left ventricular function in neonates with persistent pulmonary hypertension was then compared with that in 50 healthy neonates. ${ }^{10}$ 
Patients and methods

\section{CONTROLS}

Echocardiograms were recorded from 50 clinically healthy neonates (age range 2-64 hours, mean age 19 hours); 26 were girls and 24 boys with birth weights ranging from 2.6 to $4.5 \mathrm{~kg}$ as previously reported. ${ }^{10}$

\section{STUDY GROUP}

Echocardiograms were recorded from 23 neonates with persistent pulmonary hypertension (10 girls and 13 boys, age range 12-96 hours) whose birth weights ranged from 2.4 to $4.7 \mathrm{~kg}$. Neonates were included in this study only if they fulfilled all of the following criteria: (a) full term gestation ( $>38$ weeks); (b) normal birth weight; (c) no evidence of anatomical cardiac abnormality either clinically or by $M$-mode and cross sectional echocardiography (when the diagnosis was uncertain and congenital heart disease suspected, as it was in two infants, cardiac catheterisation was performed; this showed pulmonary hypertension and normal cardiac anatomy); (d) pulmonary arterial oxygen pressure $\left(\mathrm{PaO}_{2}\right)<50 \mathrm{~mm} \mathrm{Hg}$ on maximum ventilatory support with a fractional inspired oxygen content $\left(\mathrm{FIO}_{2}\right)$ of $100 \%$, an inspiratory pressure above $32 \mathrm{~cm}$ of water, and positive end expiration pressure (PEEP) of 4-10 cm of water; and (e) sinus rhythm with no electrocardiographic evidence of conduction disturbances.
These strict criteria were selected so that there was no doubt that all the neonates in this study had persistent pulmonary hypertension, but in so doing we included those with the most severe disease which may represent only the severe end of this disease spectrum. Table 1 shows individual patient data, respiratory assistance, blood gas pressures, blood glucose concentrations, adjuvant drug treatment, and clinical outcome.

\section{ECHOCARDIOGRAPHY}

Echocardiograms were obtained with a Hoffrel ultrasonoscope using an Aerotech $5 \mathrm{mHz}$ non-focused $6 \mathrm{~mm}$ diameter transducer providing an axial resolution of $0.4 \mathrm{~mm}$ with a repetition frequency of 1000 cycles/s. Recordings were made with an Irex multichannel physiological recorder at paper speeds of 75-100 mm/s with a simultaneous electrocardiographic lead chosen to demonstrate most clearly early ventricular depolarisation ( $Q$ waves). A true maximal minor axis of the left ventricular cavity was obtained by scanning from the apex of the left ventricle to the aorta and left atrium from a perpendicular recording position of the mitral valve echo. Once the mitral ring echo was identified the transducer was tilted inferiorly until strong ventricular and septal endocardial echoes were visualised (Fig. 1).

Echocardiograms were digitised by one of us without any knowledge of the clinical findings. Although

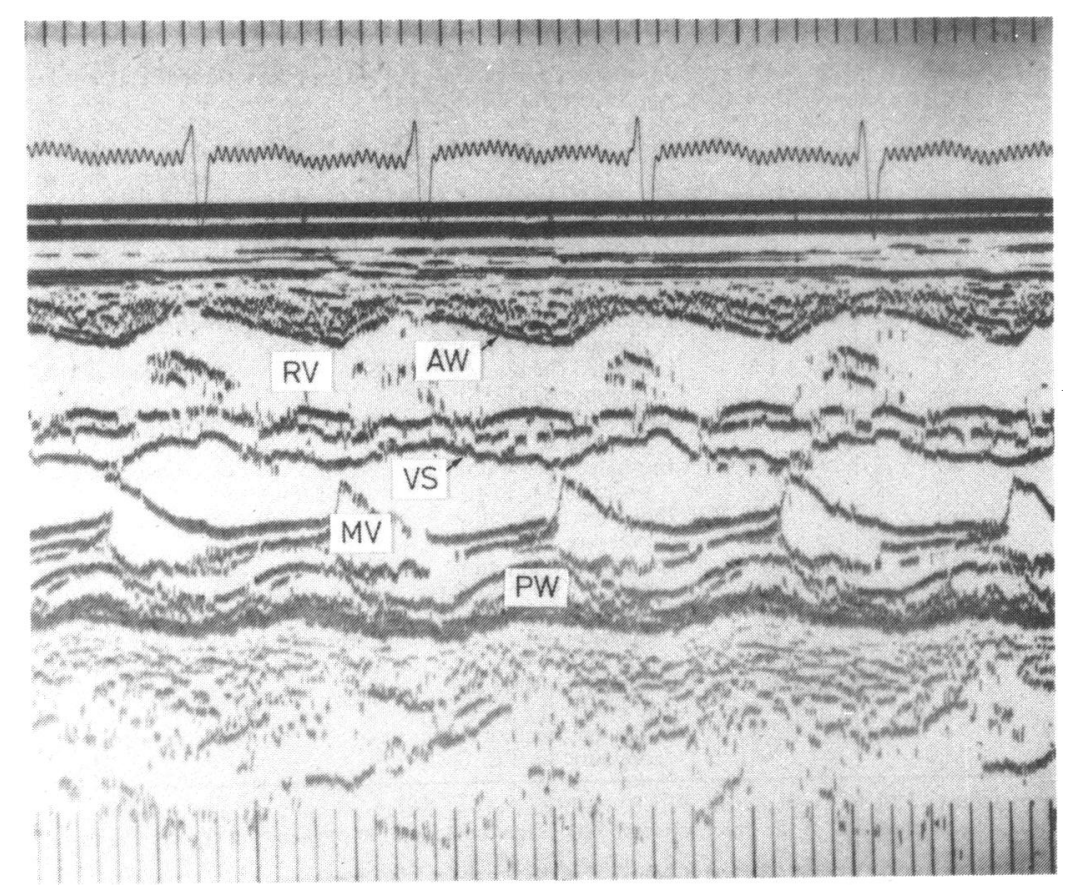

Fig. 1 Echocardiogram of a healthy neonate showing right and left ventricles. $A W$, anterior wall; $V S$, septum; $P W$, posterior wall; $M V$, mitral valve; $R V$, right ventricle. 
Table 1 Summary of clinical data

\begin{tabular}{|c|c|c|c|c|c|c|c|c|c|c|}
\hline $\begin{array}{l}\text { Case } \\
\text { No }\end{array}$ & $\begin{array}{l}\text { Birth } \\
\text { weight } \\
\text { (kg) }\end{array}$ & $\begin{array}{l}\text { Age } \\
\text { at } \\
\text { echo } \\
\text { (h) }\end{array}$ & Admission diagnosis & $\begin{array}{l}\mathrm{FIO} / \mathrm{PaO}_{2} \\
(\% / \mathrm{kaa})\end{array}$ & $\begin{array}{l}\mathrm{PaCO}_{2} \\
\left(\% / k \mathrm{~Pa}^{2}\right.\end{array}$ & $p H$ & $\begin{array}{l}\text { Blood } \\
\text { glucose } \\
\text { concen- } \\
\text { tration } \\
\text { (mmolll) }\end{array}$ & $\begin{array}{l}\text { Respiratory assistance } \\
\text { (pressures in } \mathrm{mm} \mathrm{H}_{2} \mathrm{O} \text { ) }\end{array}$ & Tolazoline & Outcome \\
\hline 1 & $2 \cdot 7$ & 72 & Meconium aspiration & $1 \cdot 0 / 5 \cdot 6$ & 5.8 & $7 \cdot 36$ & 2.5 & $\begin{array}{l}\text { Intubated (inspiration } \\
\text { pressure 34, PEEP 6) }\end{array}$ & No & Discharged well at 12 days \\
\hline 2 & $4 \cdot 6$ & 16 & $\begin{array}{l}\text { PPHN, infant of } \\
\text { diabetic mother }\end{array}$ & $1 \cdot 0 / 4 \cdot 6$ & $7 \cdot 7$ & $7 \cdot 24$ & $4 \cdot 5$ & $\begin{array}{c}\text { Intubated (inspiration } \\
\text { pressure 36, PEEP 6) }\end{array}$ & No & $\begin{array}{l}\text { Died at } 24 \text { h: necropsy } \\
\text { showed } L V H+R V+L V \\
\text { papillary muscle necros } \\
\text { and subendocardial } \\
\text { haemorrhage and } \\
\text { infarction }\end{array}$ \\
\hline 3 & $3 \cdot 2$ & 36 & PPHN, ?CHD & $1 \cdot 0 / 6 \cdot 0$ & 6.6 & $7 \cdot 34$ & 4.9 & $\begin{array}{l}\text { Intubated (inspiration } \\
\text { pressure 30, PEEP 4) }\end{array}$ & $\begin{array}{l}\text { Yes and } \\
\text { dopamine }\end{array}$ & Discharged well at 16 days \\
\hline 4 & $3 \cdot 5$ & 48 & $\begin{array}{l}\text { CHF, ?PPHN, birth } \\
\text { asphyxia }\end{array}$ & $1 \cdot 0 / 4 \cdot 0$ & $9 \cdot 4$ & $7 \cdot 26$ & 1.9 & $\begin{array}{l}\text { Intubated (inspiration } \\
\text { pressure } 30 \text { ) }\end{array}$ & No & $\begin{array}{l}\text { Died at } 9 \text { days: necropsy co } \\
\text { showed LVH, subendo-O } \\
\text { cardial haemorrhage } \\
\text { around RV and LV } \\
\text { papillary muscles }\end{array}$ \\
\hline 5 & $3 \cdot 2$ & 12 & $\begin{array}{l}\text { ?Pneumonia, PPHN, } \\
\text { ?pneumothorax }\end{array}$ & $1 \cdot 0 / 4 \cdot 5$ & $8 \cdot 1$ & $7 \cdot 14$ & $5 \cdot 3$ & $\begin{array}{l}\text { Intubated (inspiration } \\
\text { pressure 40, PEEP 4) }\end{array}$ & Yes & $\begin{array}{l}\text { Died at } 2 \text { days. No necropsio } \\
\text { became cyanosed and } \\
\text { hypotensive led to cardiat } \\
\text { arrest }\end{array}$ \\
\hline 6 & $2 \cdot 9$ & 36 & PPHN & $1 \cdot 0 / 5 \cdot 7$ & 8.8 & $7 \cdot 16$ & $3 \cdot 7$ & $\begin{array}{l}\text { Intubated (inspiration } \\
\text { pressure 40, PEEP 6) }\end{array}$ & Yes & 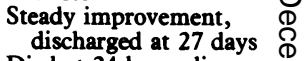 \\
\hline 7 & 3.7 & 12 & $\begin{array}{l}\text { Aspiration, infant of } \\
\text { diabetic mother, } \\
\text { CHD, ?PPHN }\end{array}$ & $1 \cdot 0 / 5 \cdot 2$ & $7 \cdot 2$ & $7 \cdot 25$ & 5.9 & $\begin{array}{l}\text { Intubated (inspiration } \\
\text { pressure 40, PEEP 6) }\end{array}$ & Yes & $\begin{array}{l}\text { Died at } 24 \mathrm{~h} \text { : cardiac } \\
\text { catheterisation: RV 80/ } \\
\text { PA 80/40, LV 80/8, A0 } \\
\text { 80/40. R to L shunt at } \\
\text { PDA, normal cardiac } \\
\text { anatomy. No necropsy }\end{array}$ \\
\hline 8 & $3 \cdot 3$ & 18 & $\begin{array}{l}\text { Infant of diabetic } \\
\text { mother, CHF, PPHN }\end{array}$ & $1 \cdot 0 / 5 \cdot 7$ & $7 \cdot 8$ & $7 \cdot 25$ & 3.6 & $\begin{array}{l}\text { Intubated (inspiration } \\
\text { pressure 40, PEEP 10) }\end{array}$ & No & Discharged well at 17 days \\
\hline 9 & $2 \cdot 8$ & 24 & Aspiration, ?pneumo- & $1 \cdot 0 / 6 \cdot 4$ & $7 \cdot 2$ & $7 \cdot 27$ & 5.9 & $\begin{array}{l}\text { Intubated (inspiration } \\
\text { pressure 48, PEEP 4) }\end{array}$ & $\begin{array}{l}\text { Yes and } \\
\text { dopamine }\end{array}$ & Discharged well at 27 day? \\
\hline 10 & $3 \cdot 1$ & 12 & CHD, ?PPHN & $1 \cdot 0 / 6 \cdot 1$ & $7 \cdot 2$ & $7 \cdot 40$ & $5 \cdot 6$ & $\begin{array}{l}\text { Intubated (inspiration } \\
\text { pressure 40, PEEP 4) }\end{array}$ & No & Discharged well at 11 day \\
\hline 11 & $3 \cdot 7$ & 48 & $\begin{array}{l}\text { Meconium aspiration, } \\
\text { infant of diabetic } \\
\text { mother }\end{array}$ & $1 \cdot 0 / 4 \cdot 6$ & $13 \cdot 1$ & 6.97 & $3 \cdot 2$ & $\begin{array}{l}\text { Intubated (inspiration } \\
\text { pressure 40) }\end{array}$ & $\begin{array}{l}\text { Yes and } \\
\text { epinephrine }\end{array}$ & $\begin{array}{l}\text { Died at } 9 \text { days: necropsy, } \\
\text { e } \mathrm{LVH} \text { and mild LV } \\
\text { dilatation }\end{array}$ \\
\hline 12 & $3 \cdot 2$ & 8 & Aspiration, ?PPHN & $1 \cdot 0 / 4 \cdot 0$ & $8 \cdot 6$ & $7 \cdot 12$ & 3.9 & $\begin{array}{l}\text { Intubated (inspiration } \\
\text { pressure 32) }\end{array}$ & No & Discharged well at 14 day $\frac{\bar{\sigma}}{3}$ \\
\hline 13 & $4 \cdot 1$ & 12 & ?TGA, ?PPHN & $1 \cdot 0 / 4 \cdot 6$ & 6.6 & $7 \cdot 28$ & $4 \cdot 8$ & $\begin{array}{l}\text { Intubated (inspiration } \\
\text { pressure 36, PEEP 8) }\end{array}$ & No & $\begin{array}{l}\text { Cardiac catheterization: } \\
\text { RV } 70 / 7, \mathrm{PA} 70 / 49 \text {, LV } \\
65 / 12, \mathrm{Ao} 63 / 48, \mathrm{R} \text { to } \\
\text { shunt at } \mathrm{PDA} \text {, normal } \\
\text { anatomy; discharged weed } \\
\text { at } 22 \text { days }\end{array}$ \\
\hline 14 & $4 \cdot 0$ & 12 & ?PPHN, ?CHF & $1 \cdot 0 / 5 \cdot 3$ & 6.5 & $7 \cdot 33$ & $4 \cdot 0$ & $\begin{array}{l}\text { Intubated (inspiration } \\
\text { pressure 38, PEEP 8) }\end{array}$ & $\begin{array}{l}\text { Yes and } \\
\text { epinephrine }\end{array}$ & $\begin{array}{l}\text { Progressive increase in } \\
\text { cyanosis and hypotensiog } \\
\text { died from cardiac arrest } \\
3 \text { days. No necropsy }\end{array}$ \\
\hline 15 & $3 \cdot 2$ & 12 & $\begin{array}{l}\text { Meconium aspiration, } \\
\text { ?PPHN }\end{array}$ & $1 \cdot 0 / 3 \cdot 6$ & $4 \cdot 6$ & $7 \cdot 40$ & 3.4 & $\begin{array}{l}\text { Intubated (inspiration } \\
\text { pressure 40, PEEP 6) }\end{array}$ & $\begin{array}{l}\text { Yes and } \\
\text { dopamine }\end{array}$ & \\
\hline 16 & $2 \cdot 9$ & 30 & ?Sepsis, pneumonia, & $1 \cdot 0 / 6 \cdot 5$ & $5 \cdot 7$ & $7 \cdot 27$ & $7 \cdot 8$ & $\begin{array}{l}\text { Intubated (inspiration } \\
\text { pressure 32, PEEP 6) }\end{array}$ & No & Discharged well at 30 daye \\
\hline 17 & $4 \cdot 1$ & 24 & ?PPHN & $1 \cdot 0 / 5 \cdot 4$ & 4.6 & $7 \cdot 39$ & 4.7 & $\begin{array}{l}\text { Intubated (inspiration } \\
\text { pressure 32) }\end{array}$ & No & Discharged well at 11 day\$ \\
\hline 18 & .5 & 24 & $\begin{array}{l}\text { ?Pneumonia, ?sepsis, } \\
\text { ?PPHN } \\
\text { PPHN }\end{array}$ & $1 \cdot 0 / 5 \cdot 7$ & $6 \cdot 1$ & $7 \cdot 29$ & $4 \cdot 3$ & $\begin{array}{l}\text { Intubated (inspiration } \\
\text { pressure 34, PEEP 4) }\end{array}$ & $\begin{array}{l}\text { Yes and } \\
\text { dopamine }\end{array}$ & Discharged well at 19 days \\
\hline 19 & 3.9 & 36 & PPHI & $1.0 / 4 \cdot 8$ & 0.1 & 1.40 & 3.9 & $\begin{array}{l}\text { Intubated (inspiration } \\
\text { pressure 32) }\end{array}$ & No & jischarged well at $/$ \\
\hline 20 & $\cdot 3$ & 120 & iration & $1.0 / 6 \cdot 0$ & 6.6 & 1.32 & $4 \cdot 4$ & $\begin{array}{l}\text { Intubated (inspiration } \\
\text { pressure 40, PEEP 6) }\end{array}$ & No & Discharged w \\
\hline 21 & $3 \cdot 2$ & 24 & 'HN & $1.0 / 4.9$ & 6.8 & $7 \cdot 33$ & 3.6 & $\begin{array}{l}\text { Intubated (inspiration } \\
\text { pressure 34) }\end{array}$ & $\begin{array}{l}\text { Yes and } \\
\text { dopamine }\end{array}$ & $\begin{array}{l}\text { Died at } 3 \text { days: hypotensiog } \\
\text { and increasing cyanosis } \\
\text { led to cardiac arrest }\end{array}$ \\
\hline 22 & $4 \cdot 7$ & 24 & $\begin{array}{l}\text { Asphyxia, meconium } \\
\text { aspiration }\end{array}$ & $1 \cdot 0 / 5 \cdot 2$ & $5 \cdot 7$ & $7 \cdot 26$ & 3.0 & $\begin{array}{l}\text { Intubated (inspiration } \\
\text { pressure 36) }\end{array}$ & No & Discharged well at 15 day \\
\hline 23 & $2 \cdot 7$ & 48 & PHN, ?CHD & .9 & 4.9 & $7 \cdot 38$ & $2 \cdot 0$ & $\begin{array}{l}\text { Intubated (inspiration } \\
\text { pressure 40, PEEP 8) }\end{array}$ & $N$ & \\
\hline
\end{tabular}

CHD, congenital heart defect; CHF, congestive heart failure; LV, left ventricular; PEEP, positive end expiratory pressure; PPHN, persistent pulmona尊 hypertension of the newborn; RV, right ventricular; TGA, transposition of the great arteries; $\mathrm{FIO}_{2}$, fractional inspired oxygen; PaCO ${ }_{2}$, arterial carbon dioxide pressure; $\mathrm{PaO}_{2}$, arterial oxygen pressure.

Conversion: SI to traditional units-glucose: $1 \mathrm{mmol} / 1 \approx 18.01 \mathrm{mg} / 100 \mathrm{ml}$; arterial pressure: $1 \mathrm{kPa} \approx 7.5 \mathrm{~mm} \mathrm{Hg}$. 
Control
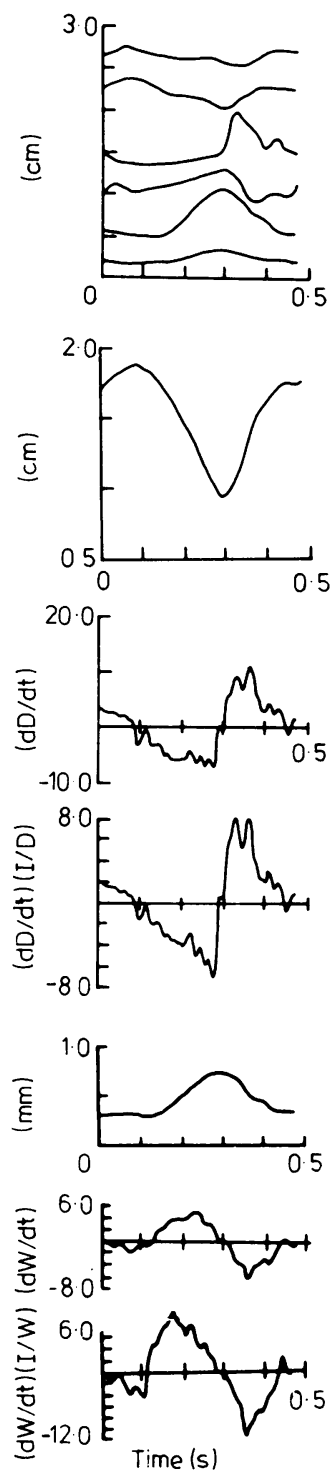

PPHN

(a)

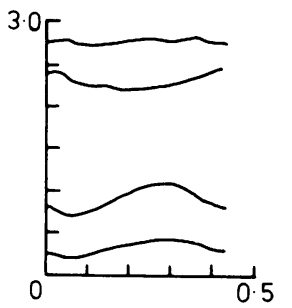

(b)

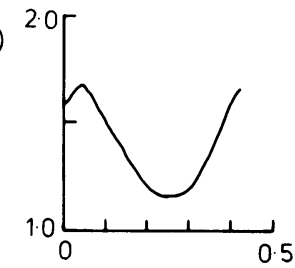

(c)

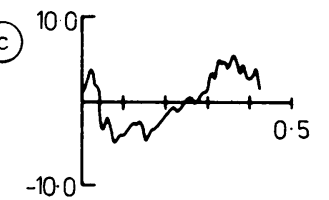

(d)

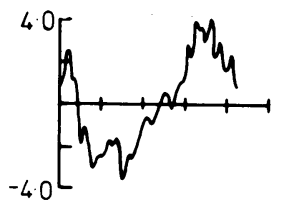

(e)

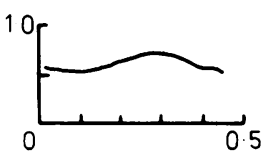

(f)

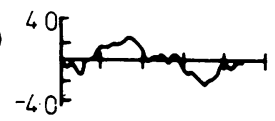

(9)

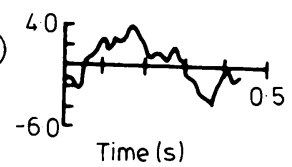

Fig. 2 Digitised left ventricular echocardiograms of healthy neonate (control) and a neonate with persistent pulmonary hypertension $(P P H N):(a)$ showing the $X Y$ coordinates from the echocardiogram, (b) the continuous left ventricular dimension, (c) the rate of change of left ventricular dimension $(d D / d t),(d)$ the normalised rate of change of left ventricular dimension $(d D / d t)(I / D),(e)$ the continuous left ventricular wall thickness, $(f)$ the rate of change of wall thickness, $(d W / d t)$ and $(g)$ the normalised rate of change of wall thickness $(d W / d t)(1 / W)$.

serial echo examinations were performed in each patient, only the initial result was included in this analysis. Only echoes that were clear and continuous

throughout the cardiac cycle were digitised as described ${ }^{9-11}$ using a Digisonics digitiser and microprocessor. To minimise errors the depth scale was expanded so that each $\mathrm{cm}$ exceeded $15 \mathrm{~mm}$. Echoes were calibrated with points defining a time interval of $1 \mathrm{~s}$, a depth of $3 \mathrm{~cm}$, and two successive $Q$ waves on the EKG, enclosing the cardiac cycle to be analysed. Data points were generated at intervals of $10 \mathrm{~ms}$ so that strings of XY coordinates were obtained for the abovementioned surface boundaries. From these data plots were obtained from an online incremental plotter of continuous left ventricular caṽity dimension and posterior left ventricular wall thickness and their respective rates of change expressed in $\mathrm{cm} / \mathrm{s}$ or normalised by dividing by instantaneous cavity dimension or posterior wall thickness (Fig. 2). From these plots the following measurements were made: (a) heart rate (beats/minute); (b) dimensions-(i) end systolic and end diastolic left ventricular cavity dimension (mm), (ii) end systolic and end diastolic posterior wall thickness (mm), and (iii) end diastolic relative wall thickness (ratio of posterior wall thickness to left ventricular cavity radius at end diastole (h/R)); (c) left ventricular systolic function-(i) percentage left ventricular cavity shortening, (ii) peak velocity of circumferential fibre shortening (peak VCF/s), (iii) percentage systolic thickening of the posterior left ventricular wall, and (iv) normalised peak rate of posterior left ventricular wall thickening (per second); and (d) left ventricular diastolic function-(i) peak rate of increase in left ventricular dimension $(\mathrm{cm} / \mathrm{s})$, (ii) normalised peak rate of left ventricular wall thinning $\left(\mathrm{s}^{-1}\right)$, (iii) duration of rapid filling (ms) defined as the time interval from minimum left ventricular cavity dimension to that at which the peak rate of increase in left ventricular dimension fell to $20 \%$ of its peak value, ${ }^{9}$ and (iv) duration of the isovolumic relaxation period (ms) defined as the time interval from minimum left ventricular dimension to the onset of the initial separation of the mitral valve leaflets.

\section{REPRODUCIBILITY AND STATISTICAL METHOD}

Although the theoretical axial resolution of the $5 \mathrm{mHz}$ transducer driven by the Hoffrell ultrasonoscope was $0.4 \mathrm{~mm}$ we recorded wall thickness and left ventricular dimensions from the online printer to the nearest millimetre.

The significance of differences between the controls and the study group was assessed using the unpaired Student's $t$ test. Intraobserver beat to beat variability in left ventricular dimension and its rate of change was $0-7 \%$ (mean $5 \%$ ). The interobserver error in the same measurements among four individuals varied from 0 to $12 \%$ (mean $7 \%$ ), provided that there were optimal expansion of the depth scale and high paper speeds. 


\section{Results}

\section{HEART RATE}

Heart rates in the controls varied from 110 to 146 beats/minute (mean 124), which were similar to those in the study group in whom heart rate varied from 108 to 150 beats/minute (mean 127), enabling a comparison to be made of cavity and regional ventricular dynamics.

\section{DIMENSIONS}

End systolic and end diastolic left ventricular cavity size, wall thicknesses, and relative wall thickness at end diastole for the study group and controls are shown in Table 2. End diastolic and end systolic left ventricular dimensions in the two groups varied over the same wide range; however, while the mean end diastolic dimension was normal in the study group mean end systolic dimension was increased $(p<0.03)$ (Table 2) (Fig.3). Left ventricular wall thicknesses at end systole and end diastole were recorded to the nearest millimetre. Although differences in wall thicknesses between the study group and the controls were small, all records were digitised by only one of us who had no knowledge of the clinical details, thus obviating interobserver error but incurring a possible mean beat to beat variability of $5 \%$ for each group. Nevertheless, mean values for left ventricular wall thicknesses at end diastole were significantly increased in the study group compared with the controls $(p<0.001)$ (Fig. 3). In addition, diastolic relative wall thickness or $h / R$ ratio was also significantly increased in the study group $(\mathbf{p}<0.001)$ (Fig. 3) (Table 2).
LEFT VENTRICULAR SYSTOLIC FUNCTION (FIG. 3) Although both percentage left ventricular cavity shortening and peak velocity of circumferential fibre shortening varied over a wide range, the mean values for the study group were significantly lower $(p<0.02)$ compared with those for the controls (Table 2). Mean percentage systolic wall thickening was lower $(p<0.001)$ and regional dynamics assessed as normalised peak rate of systolic wall thickening were scattered over the normal range, but the mean value for the study group was significantly different from that for the controls $(p<0.001)$ (Table 2). Thus both left ventricular cavity and regional systolic function in the study group were appreciably impaired overall.

\section{DIASTOLIC VENTRICULAR FUNCTION (FIG. 3)}

There was little overlap of the peak rates of increase in left ventricular cavity diameter in diastole and the peak rates of left ventricular wall thinning between the study group and the controls, and the mean values were significantly decreased in the former $(p<0.001)$. In addition the duration of the rapid filling period was increased $(p<0.001)$ (Table 2). These abnormal left ventricular filling characteristics are shown on the plot of continuous left ventricular dimensions and its first derivative (Fig. 2); left ventricular filling in the study group was not only slowed but also prolonged, with shortening or abolition of the normal period of diastasis. The isovolumic relaxation period, which we were able to measure in only 14 patients as the time interval from minimum left ventricular dimension to mitral valve opening, was also significantly longer in the study group than in the controls (Table 2) suggesting reduced left ventricular diastolic compliance.

Table 2 Left ventricular cavity and wall dynamics in study group and controls. Results are means $\pm S D$

\begin{tabular}{|c|c|c|c|c|}
\hline & \multicolumn{2}{|c|}{ Study group $(n=23)$} & \multirow{2}{*}{$\begin{array}{l}\text { Total } \\
\text { study } \\
\text { group }\end{array}$} & \multirow[b]{2}{*}{$\begin{array}{l}\text { Controls } \\
(n=50)\end{array}$} \\
\hline & $\begin{array}{l}\text { Survivors } \\
(n=16)\end{array}$ & $\begin{array}{l}\text { Non-survivors } \\
(n=7)\end{array}$ & & \\
\hline $\begin{array}{l}\text { End diastolic LV dimension }(\mathrm{mm}) \\
\text { End systolic LV dimension }(\mathrm{mm}) \\
\% \mathrm{LV} \text { shortening fraction } \\
\text { Peak VCF/s } \\
\text { Peak LV filling rate dD/dt diastole }(\mathrm{cm} / \mathrm{s}) \\
\text { Duration of rapid filling period }(\mathrm{ms}) \\
\text { Isovolumic relaxation period }\end{array}$ & $\begin{array}{c}17 \cdot 5 \pm 3 \cdot 4 \\
11 \cdot 8 \pm 2 \cdot 7 \\
33 \pm 9 \\
3 \cdot 0 \pm 0 \cdot 9 \\
3 \cdot 9 \pm 1 \cdot 3 \\
171 \pm 30\end{array}$ & $\begin{array}{c}15 \cdot 6 \pm 5 \cdot 0 \\
10 \cdot 0 \pm 3 \cdot 7 \\
36 \pm 5 \\
3 \cdot 7 \pm 0 \cdot 8 \\
3 \cdot 8 \pm 0.8 \\
184 \pm 37\end{array}$ & $\begin{array}{l}17 \cdot 3 \pm 3 \cdot 5 \\
11 \cdot 7 \pm 2 \cdot 9^{\star \star \star \star \star} \\
33 \pm 8^{\star \star} \\
3 \cdot 0 \pm 0 \cdot 9^{\star \star \star \star} \\
4 \cdot 0 \pm 1 \cdot 1^{\star} \\
177 \pm 33 \\
40 \pm 15^{\star \star \star} \\
(n=14)\end{array}$ & $\begin{array}{c}17 \cdot 3 \pm 2 \cdot 0 \\
9 \cdot 6 \pm 2 \cdot 2 \\
44 \pm 6 \\
3 \cdot 8 \pm 1 \cdot 0 \\
7 \cdot 7 \pm 2 \cdot 9 \\
138 \pm 28 \\
15 \pm 10\end{array}$ \\
\hline $\begin{array}{l}\text { Wall thickness (mm) } \\
\text { Minimum diastolic } \\
\text { Maximum systolic } \\
\text { Systolic wall thickening (\%) } \\
\text { Relative wall thickness at end diastole } \\
\text { Peak rate systolic wall thickening } \\
\text { Peak rate diastolic wall thinning }\end{array}$ & $\begin{array}{l}3 \cdot 1 \pm 0 \cdot 8 \\
5 \cdot 7 \pm 1 \cdot 1 \\
86 \pm 28 \\
0 \cdot 37 \pm 0 \cdot 09 \\
4 \cdot 1 \pm 1 \cdot 0 \\
4 \cdot 5 \pm 1 \cdot 4\end{array}$ & $\begin{array}{l}4 \cdot 0 \pm 1 \cdot 1 \\
6 \cdot 4 \pm 1 \cdot 3 \\
70 \pm 23 \\
0 \cdot 45 \pm 0.06 \\
3 \cdot 8 \pm 1 \cdot 3 \\
4 \cdot 6 \pm 1 \cdot 3\end{array}$ & $\begin{array}{l}3 \cdot 5 \pm 0.9^{\star} \\
5 \cdot 9 \pm 1 \cdot 1 \\
78 \pm 28^{\star} \\
0 \cdot 4 \pm 0.08^{\star \star} \\
3 \cdot 9 \pm 1 \cdot 1^{\star} \\
4 \cdot 6 \pm 1 \cdot 4^{\star}\end{array}$ & $\begin{array}{c}2 \cdot 5 \pm 0.6 \\
5 \cdot 4 \pm 0.8 \\
130 \pm 50 \\
0.29 \pm 0.05 \\
5 \cdot 4 \pm 1 \cdot 3 \\
8.0 \pm 2 \cdot 2\end{array}$ \\
\hline
\end{tabular}

Significant difference (study group $v$ controls): ${ }^{\star} p<0.001,{ }^{\star \star} p<0.005,{ }^{\star \star \star} p<0.01,{ }^{\star \star \star \star} p<0.02, \star \star \star \star \star p<0.08$. LV, left ventricular; VCF, velocity of circumferential fibre shortening. 

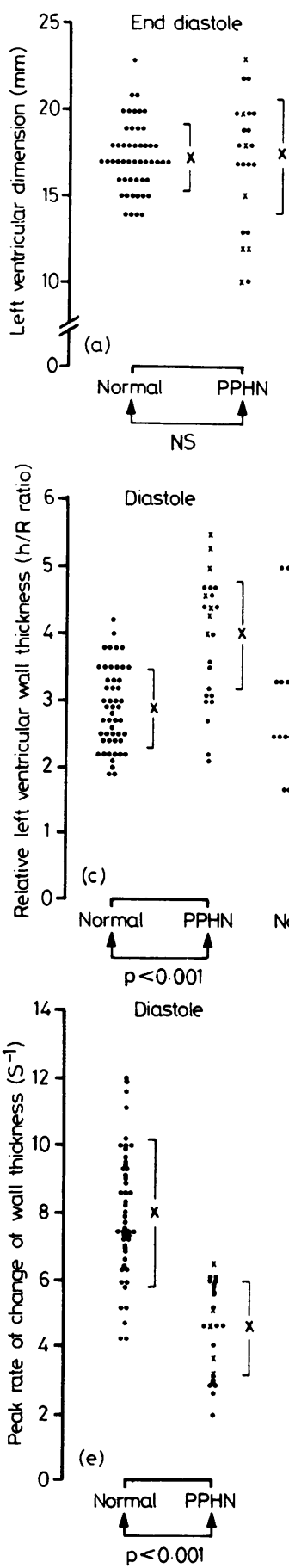

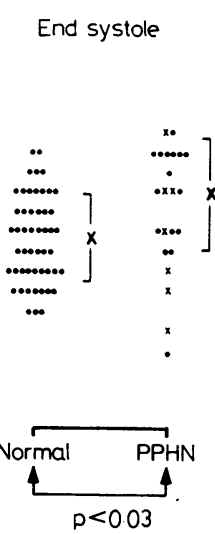

Systole
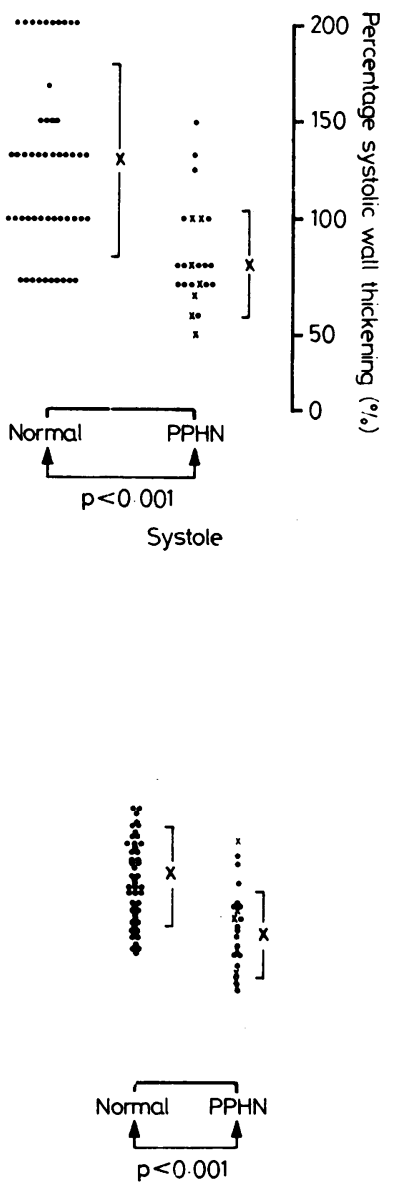

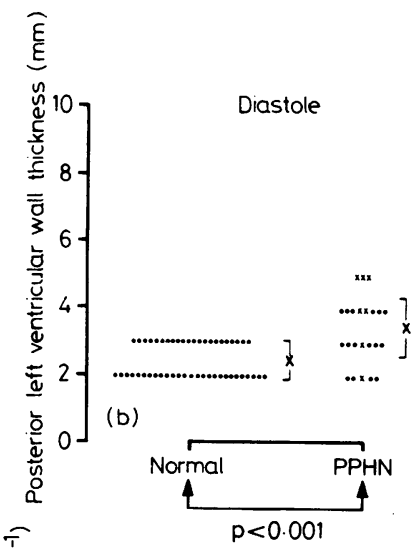

in
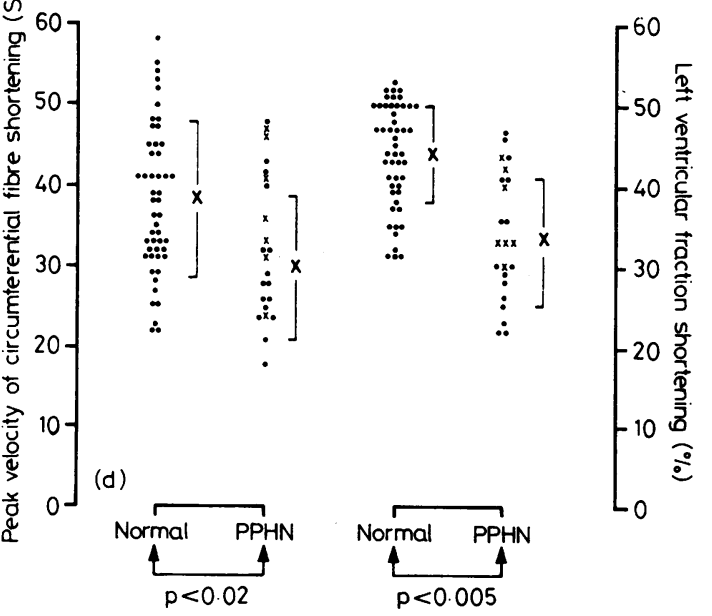

Systole
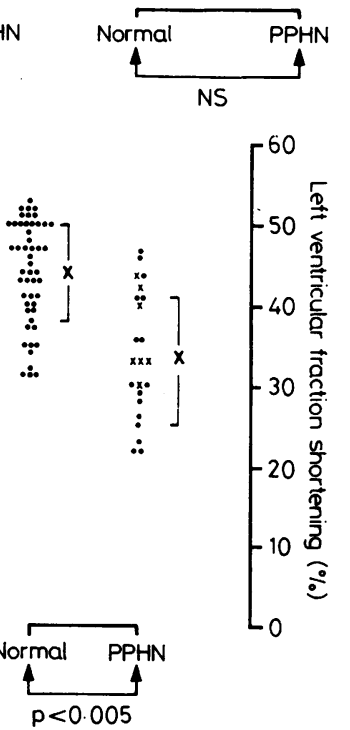

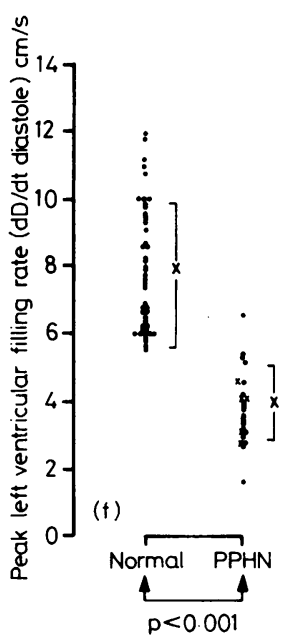

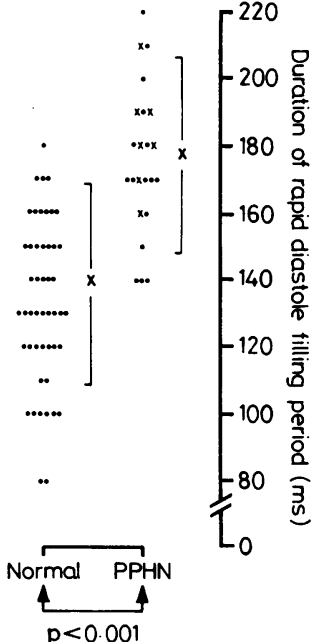

Fig. 3 Plot of (a) left ventricular cavity dimension in healthy neonates (control group) and those with PPHN (study group) at end diastole and end systole ( $x=$ non-survivors); (b) posterior left ventricular wall thickness; (c) diastolic relative wall thickness and percentage systolic wall thickening, (d) peak velocity of circumferential fibre shortening and left ventricular fractional shortening, (e) peak rate of change in lefi ventricular wall thickness in diastole, and $(f)$ peak left ventricular filling rate (dD/dt diastole) and duration of the rapid diastolic filling period. 
The study group was subdivided into those who survived and those who died. Wall and cavity dimensions and dynamics were compared in an attempt to identify any measure of left ventricular function which might be useful prognostically. There was no difference in left ventricular cavity size or wall thickness, and those who died could not be differentiated by measurements of cavity or regional systolic or diastolic function (Fig. 3). In both groups, as in the study group as a whole, there was greater impairment of diastolic than systolic cavity and regional left ventricular function.

\section{CLINICAL OUTCOME}

Of the 23 neonates in the study group, seven (30\%) died from one to nine days (mean 3.9 days) after birth (Table 1). Three of the seven neonates who died were examined at necropsy. All three had concentric left ventricular hypertrophy and one also mild left ventricular cavity dilatation. Two of the three had severe subendocardial haemorrhage and papillary muscle necrosis in both the right and left ventricles with extensive subendocardial infarction of both ventricles.

\section{Discussion}

Persistent pulmonary hypertension of the newborn has been regarded primarily as a pulmonary vascular or right heart disorder. Computer analysis of the left ventricular echocardiograms in the 23 neonates in this study showed significant abnormalities of both systolic and diastolic left ventricular function. About one quarter of the patients died despite intubation and maximum ventilatory support with increased inspiratory pressure, correction of acidaemia, and treatment with vasodilator drugs. This inordinately high mortality may have been due in part to our selecting only infants with the most severe pulmonary hypertension for inclusion in the study.

Although M-mode echocardiography permits static measurements of ventricular chamber size, a possible shortcoming in assessing dynamic left ventricular function is that only a basal slice of the ventricle is reproducibly visualised. Nevertheless, in the absence of segmental abnormalities, which we presumed to be the case in these neonates with generalised hypoxaemia, echocardiographic recordings from the base were regarded as representative of the left ventricle as a whole.

Although end diastolic left ventricular cavity size was normal, percentage fractional shortening and peak velocity of circumferential shortening varied over a wide range. While these systolic variables could not reliably identify individual neonates with persistent pulmonary hypertension, the mean values for the group as a whole were significantly lower than for the controls, indicating impaired contractile function overall. More impressive even than the abnormalities of systolic cavity function was the impairment of diastolic cavity dynamics manifested as abnormal left ventricular filling characteristics. The rate of left ventricular filling was universally decreased with virtually no overlap with the controls. The duration of the rapid diastolic filling period was also prolonged in most infants in the study group with consequent shortening or abolition of the normal period of diastasis (Fig. 2). Since the mitral valve leaflets and their motion pattern were normal and did not therefore obstruct blood flow at the left ventricular inflow tract the reduction in left ventricular filling was most likely to have been caused by decreased myocardial compliance, resulting at least in part from the concentric left ventricular hypertrophy. Further evidence for decreased left ventricular compliance in persistent pulmonary hypertension was the prolongation of isovolumic relaxation. ${ }^{413}$

Left ventricular diastolic wall thickness varied, but the mean value for the study group as a whole was significantly increased compared with that for the controls, and in addition, the presence of concentric left ventricular hypertrophy was confirmed in the three neonates who were examined at necropsy. Relative wall thickness, which is virtually constant in the normal human left ventricle from birth to old age, ${ }^{11} 14$ was significantly increased and may have resulted in part from the increased systemic vascular resistance recently reported in this disorder. ${ }^{15}$

Regional myocardial function, the integral of which determines left ventricular cavity function, was also severly abnormal. Systolic and diastolic wall dynamics, which directly reflect myocardial contraction and relaxation respectively, were both significantly reduced. This impairment in cardiac muscle function in the study group could not be accounted for by any differences in heart rate, as these were the same as in the controls. It may, however, have resulted in part from the increased wall thickness and changed cavity architecture (relative wall thickness). The greater impairment of diastolic than systolic regional function was unexplained, but it was consistent with the similarly greater impairment of diastolic cavity function, since cavity function is simply an expression of endocardial movement, the determinants of which are muscle thickening and thinning.

To determine whether this detailed computer analysis of left ventricular function could identify some measurement of regional or cavity dynamics which might prove useful in prognosis, we compared survivors with non-survivors. Systolic and diastolic cavity and regional function were, however, equally abnormal in both groups (Table 2), and no single or combination of echocardiographic measurements 
proved useful in differentiating between the two groups.

The precise aetiology of the left ventricular dysfunction in persistent pulmonary hypertension of the newborn is not resolved, but there are four important contributing factors: pulmonary hypertension by itself, alteration in left ventricular geometry by the pressure overloaded right ventricle, hypoxaemia resulting in generalised myocardial ischaemia, and metabolic acidaemia.

The effects of pulmonary hypertension by itself on left ventricular function have been evaluated in adults with pulmonary artery pressures at subsystemic values and have shown reduced rates of diastolic filling and decreased systolic performance. ${ }^{1617}$ Furthermore, in experimental animals with moderate right ventricular hypertension myocardial blood flow to the left as well as the right ventricle is significantly reduced, ${ }^{18}$ and it has been suggested that this may account for the reduced left ventricular compliance and secondary resistance to left ventricular filling. This mechanism may be concerned in the pathogenesis of left ventricular dysfunction in persistent pulmonary hypertension, in which the right ventricle often develops systemic or greater than systemic pressures.

A further possible cause of left ventricular dysfunction in persistent pulmonary hypertension is that the pressure overloaded right ventricle changes the geometry of the left ventricle by displacing it more posteriorly or by altering the direction of septal motion, thus changing the region of the left ventricle intersected by the $M$-mode echo beam. Although this is a theoretical consideration, septal motion was normal in all infants with persistent pulmonary hypertension. Moreover, previous studies in patients with pronounced right ventricular volume overload with or without septal abnormalities ${ }^{19}$ and in right ventricular pressure overload with normal septal motion ${ }^{20}$ failed to show any evidence of regional or global left ventricular dysfunction. It seems unlikely therefore that abnormal geometry was a major cause of the left ventricular dysfunction in our study group.

The role of hypoxaemia in causing myocardial ischaemia and subsequent left ventricular dysfunction is not clearly established. In the normal heart, myocardial oxygen extraction is near maximal and anerobic reserves are minimal. ${ }^{21}$ In persistent pulmonary hypertension of the newborn in which $\mathrm{PaO}_{2}$ is $<6.6 \mathrm{kPa}(<50 \mathrm{~mm} \mathrm{Hg})$, the baseline delivery is reduced which, coupled with the possible reduction in myocardial perfusion due to pulmonary hypertension $^{18}$ and the increased muscle mass from left ventricular hypertrophy, may exacerbate the imbalance between myocardial oxygen supply and demand resulting in global myocardial ischaemia.
More direct evidence for severe hypoxaemia resulting in ischaemia is provided by the subendocardial infarction which has been found at necropsy in neonates with severe cyanosis from congenital heart disease and normal coronary anatomy..$^{22-26}$ It is of particular interest that these subendocardial infarctions are present in the left as well as the right ventricle. ${ }^{26}$ It was noi until very recently, however, that myocardial infarction and papillary muscle necrosis in the right and left ventricles were recognised in neonates with severe hypoxaemia due to birth asphyxia, aspiration, intracranial haemorrhage, and hyaline membrane disease in the absence of any congenital heart disease. ${ }^{27} 28$

Myocardial ischaemia has also been shown by thallium imaging in neonates with hypoxaemia due to the respiratory distress syndrome. ${ }^{29}$ Such severe hypoxaemia is commonplace in persistent pulmonary hypertension of the newborn. Of our three neonates who were examined at necropsy, two had severe subendocardial haemorrhage and infarction in the right and left ventricles indicating myocardial ischaemia as a probable aetiological factor, which in the most severe circumstances results in infarction and when of lesser severity results in major left ventricular dysfunction.

The fourth major contributing factor to left ventricular dysfunction is metabolic acidaemia, which even in the absence of hypoxaemia may decrease myocardial contractile function. ${ }^{30} 31$ When acidaemia is accompanied by severe hypoxaemia, as it is in persistent pulmonary hypertension of the newborn, the deleterious effect is greater than with either hypoxaemia or acidaemia alone, because acidaemia potentiates the vasoconstrictor effect of hypoxaemia. ${ }^{32}$ Thus a vicious cycle ensues in which further pulmonary vasoconstriction and rise of pulmonary artery pressure causes increased right to left shunting, greater oxygen desaturation, and exacerbation of pulmonary arterial vasospasm. Although most of our patients were in relative acid base balance at the time of their echocardiograms, the effects of earlier acidaemia and hypoxaemia on left ventricular function may still have been present.

We conclude that there is severe left ventricular dysfunction in persistent pulmonary hypertension of the newborn, with consistent abnormalitites of diastolic properties which can be readily recognised by computer analysis of the echocardiogram. Unfortunately, however, no single or combination of echo measurements of left ventricular function were useful in determining prognosis in individual patients. The cause of the left ventricular dysfunction was most likely due to a combination of hypoxaemia, acidaemia, pulmonary hypertension, and possibly changes in left ventricular geometry, but we were unable to assess the respective contributions of each. 
Caution must be taken in interpreting the incidence of left ventricular dysfunction in persistent pulmonary hypertension of the newborn from this study, since this disorder has a wide spectrum of severity and the criteria we used to select our patients tended to include only those with severe disease. Finally, the echocardiographic and necropsy findings of left ventricular disease in persistent pulmonary hypertension of the newborn, although not correlating with clinical outcome, may still play a part in the high mortality rate in newborns with this disorder.

We are indebted to Eileen Slattery of the Johnson Foundation for the illustrations.

\section{References}

1 Rudolph AM, Auld PAM, Golinko RJ, Paul MH. Pulmonary vascular adjustments in the neonatal period. Pediatrics 1961; 28: 28-34.

2 Emmanouilides GC, Moss AJ, Duffie ER Jr, Adams FH. Pulmonary arterial pressure changes in human newborn infants from birth to 3 days of age. $\mathcal{F}$ Pediatr 1964; 65: 327-33.

3 Gersony WM, Duc GV, Sinclaii JC. 'P.F.C.' syndrome (persistence of the fetal circulation. [Abstract]. Circulation 1969; 40 (suppl III): 87.

4 Levin DL, Heymann MA, Kitterman JA, Gregory GA, Phibbs RH, Rudolph AM. Persistent pulmonary hypertension of the newborn infant. $\mathcal{F}$ Pediatr 1976; 89: 62630 .

5 Siassi B, Goldberg SJ, Emmanouilides GC, Higashino SM, Lewis E. Persistent pulmonary vascular obstruction in newborn infants. F Pediatr 1971; 78: 610-5.

6 Riggs T, Hirschfeld S, Fanaroff A, Liebman H, Fletcher B, Meyer RA. Persistence of fetal circulation syndrome: an echocardiographic study. $\mathcal{F}$ Pediatr 1977; 91: 626-31.

7 Rowe RD, Hoffman T. Transient myocardial ischemia of the newborn infant: a form of severe cardiorespiratory distress in full-term infants. F Pediatr 1972; 81: 243-50.

8 Riemenschneider TA, Nielsen HC, Ruttenberg HD, Jaffe RB. Disturbances of the transitional circulation: spectrum of pulmonary hypertension and myocardial dysfunction. $\mathcal{F}$ Pediatr 1976; 89: 622-5.

9 Gibson DG, Brown D. Measurement of instantaneous left ventricular dimension and filling rate in man using echocardiography. Br Heart $\mathcal{f}$ 1973; 35: 1141-9.

10 St John Sutton MG, Hagler DJ, Tajik AJ, Giuliani ER, Seward JB, Ritter DG, Ritman EL. Cardiac function in the normal newborn-additional information by computer analysis of the $\mathbf{M}$-mode echocardiogram. Circulation 1978; 57: 1198-204.

11 St John Sutton MG, Marier DL, Oldershaw PJ, Sacchetti $R$, Gibson DG. Effect of age related changes in chamber size, wall thickness, and heart rate on left ventricular function in normal children. Br Heart $\mathcal{F}$ 1982; 48: 342-51.

12 St John Sutton MG, Tajik AJ, Gibson DG, Brown DJ, Seward JB, Giuliani ER. Echocardiographic assessment of left ventricular filling and septal and posterior wall dynamics in idiopathic hypertrophic subaortic stenosis. Circulation 1978; 57: 512-20.

13 Gibson DG, Traill TA, Hall RJC, Brown DJ. Echocardiographic features of secondary left ventricular hypertrophy. Br Heart $\mathcal{F}$ 1979; 41: 54-9.

14 St John Sutton MG, Reichek N, Lovett J, Kastor JA, Giuliani ER. Effects of age, body size and blood pressure on the normal human left ventricle [Abstract]. Circulation 1980; 62 (suppl III): 305.

15 Milstein JM, Goetzman BW, Riemenschneider TA, Wennberg RP. Increased systemic vascular resistance in neonates with pulmonary hypertension. Am $\mathcal{f}$ Cardiol 1979; 44: 1159-62.

16 McLaurin LP, Gibson TC, Waider W, Grossman W, Craige E. An appraisal of mitral valve echocardiograms mimicking mitral stenosis in conditions with right ventricular pressure overload. Circulation 1973; 48: 801-9.

17 Krayenbuehl HP, Turina J, Hess $O$. Left ventricular function in chronic pulmonary hypertension. Am $\mathcal{F}$ Cardiol 1978; 41: 1150-8.

18 Fixler DE, Archie JP, Ullyot DJ, Buckberg GD, Hoffman JIE. Effects of acute right ventricular systolic hypertension on regional myocardial flow in anesthetized dogs. Am Heart $\mathcal{Y}$ 1973; 85: 491-500.

19 St John Sutton MG, Tajik AJ, Mercier L-A, Seward JB, Giuliani ER, Ritman EL. Assessment of left ventricular function in secundum atrial septal defect by computer analysis of the M-mode echocardiogram. Circulation 1979; 60: 1082-90.

20 Likoff MJ, St John Sutton MG, Weber KT, Janicki JS, Reichek N. The effect of chronic pulmonary hypertension on left ventricular size and dynamics [Abstract]. Cir. culation 1982; 66 (suppl 2): 327.

21 Berne RM, Rubio R. Coronary circulation. In: Berne RM, Sprakelakis N, eds. Handbook of physiology, Section 2. The cardiovascular system. Baltimore: Williams and Wilkins, 1979: 873-9.

22 Naeye RL, Letts HW. The effects of prolonged neonatal hypoxemia on the pulmonary vascular bed and heart. Pediatrics 1962; 30: 902-8.

23 Franciosi RA, Blanc WA. Myocardial infarcts in infants and children: 1. A necropsy study in congenital heart disease. F Pediatr 1968; 73: 309-19.

24 Esterly JR, Oppenheimer EH. Some aspects of cardiac pathology in infancy and childhood. IV. Myocardial and coronary lesions in cardiac malformations. Pediatrics 1967; 39: 896-903.

25 Richard R, Benirschke K. Myocardial infarction in the perinatal period. $\mathcal{F}$ Pediatr 1959; 55: 706-12.

26 Mehran-Pour M, Hirschfeld S, Francioli M, Liebman J. Left ventricular myocardial infarction in tetralogy of $\mathrm{Fal}$ lot. Am $\mathcal{F}$ Dis Child 1978; 132: 1217-8.

27 Setzer E, Ermocilla R, Tonkin I, John E, Sansa M, Cassady G. Papillary muscle necrosis in a neonatal autopsy population: incidence and associated clinical manifestations. F Pediatr 1980; 96: 289-94.

28 Donnelly WH, Bucciarelli RL, Nelson RM. Ischemic papillary muscle necrosis in stressed newborn infants. $\mathcal{F}$ Pediatr 1980; 96: 295-300.

29 Finley JP, Howman-Giles RB, Gilday DL, Bloom KR, Rowe RD. Transient myocardial ischemia of the newborn infant demonstrated by thallium myocardial imag- 
ing. F Pediatr 1979; 94: 263-70.

30 Rudolph AM, Yuan S. Response of the pulmonary vasculature to hypoxia and $\mathrm{H}^{+}$ion concentration changes. $\mathcal{F}$ Clin Invest 1966; 45: 399-411.

31 Enson Y, Giuntine C, Lewis ML, Morris TQ, Ferrer MI, Harvey RN. The influence of hydrogen ion concentration and hypoxia on the pulmonary circulation. $f$ Clin Invest $1964 ;$ 43: 1146-62.
32 Downing SE, Talner NS, Gardner TH. The influences of hypoxemia and acidemia on left ventricular function. Am f Physiol 1966; 210: 1327-34.

Requests for reprints to Dr Martin G St John Sutton, Division of Cardiology, Room 959, Gates Building, Hospital of the University of Pennsylvania, 3400 Spruce Street, Philadelphia, PA 19104, USA. 